\title{
Produção e desenvolvimento de jogos didáticos no ensino de Química: Caminhos alternativos adotados com relação a Educação Inclusiva
}

Production and development of didactic games in the teaching of Chemistry: Alternative paths adopted in relation to Inclusive Education

Producción y desarrollo de juegos educativos em la enseñanza de la Química: Vías alternativas adoptadas em relación con la Educación Inclusiva

\author{
Rodrigo da Vitória Gomes \\ ORCID: https://orcid.org/0000-0002-7171-695X \\ Universidade Federal do Paraná, Brasil \\ E-mail: rodrigodavitoriagomes@gmail.com \\ Mayki Jardim Sivico \\ ORCID: https://orcid.org/0000-0002-1747-5008 \\ Universidade Federal do Espírito Santo, Brasil \\ E-mail: mayki.0809@gmail.com \\ Lorena Alves Ventura \\ ORCID: https://orcid.org/0000-0002-4890-2666 \\ Universidade Federal do Espírito Santo, Brasil \\ E-mail: lorenaventura.ufes@gmail.com \\ Ana Nery Furlan Mendes \\ ORCID: https://orcid.org/0000-0001-6488-5483 \\ Universidade Federal do Espírito Santo, Brasil \\ E-mail: ana.n.mendes@ufes.br
}

\begin{abstract}
Resumo
A apropriação dos conceitos científicos no Ensino de Química é bastante expressiva, desta forma, o professor como mediador desse processo, deve propor e desenvolver metodologias alternativas, que visam potencializar o aprendizado do aluno em sala de aula. Entretanto, é necessário compreender, quais propostas metodológicas se desenvolvem, e quais caminhos alternativos adotados com relação a educação inclusiva. Assim, este estudo traz uma pesquisa qualitativa do tipo bibliográfica, buscando fazer um levantamento dos trabalhos submetidos nos anais do Encontro Nacional de Química (ENEQ), destinado a Mostra de Materiais Didáticos de Química (MOMADIQ), que envolvem práticas inclusivas de ensino. Os resultados produzidos discutem a constituição dos processos coletivos, que refletem a importância da produção e desenvolvimento dos jogos didáticos, na formação do sujeito, tanto na base conceitual dos conhecimentos científicos, quanto na construção da subjetividade.
\end{abstract}

Palavras-chave: Metodologias alternativas; Educação inclusiva; Ensino; Práticas inclusivas.

\begin{abstract}
The appropriation of scientific concepts in Chemistry Teaching is quite expressive, thus, the teacher as a mediator of this process, should propose and develop alternative methodologies, which aim to enhance student learning in the classroom. However, it is necessary to understand which methodological proposals are developed, and which alternative paths are adopted in relation to inclusive education. Thus, this study brings a qualitative bibliographical research, seeking to survey the papers submitted in the annals of the National Meeting of Chemistry (ENEQ), intended for the Exhibition of Teaching Materials for Chemistry (MOMADIQ), involving inclusive teaching practices. The results produced discuss the constitution of collective processes, which reflect the importance of the production and development of didactic games, in the formation of the subject, both in the conceptual basis of scientific knowledge, and in the construction of subjectivity.
\end{abstract}

Keywords: Alternative methodologies; Inclusive education; Teaching; Inclusive practices.

\section{Resumen}

La apropiación de los conceptos científicos en la Enseñanza de la Química es bastante significativa, por lo tanto, el profesor como mediador de este proceso, debe proponer y desarrollar metodologías alternativas, que apunten a potenciar el aprendizaje de los alumnos en el aula. Sin embargo, es necesario comprender qué propuestas metodológicas se desarrollan y qué caminos alternativos se adoptan en relación con la educación inclusiva. Así, este estudio trae una investigación bibliográfica cualitativa, buscando hacer un relevamiento de los trabajos presentados en los anales del 
Encuentro Nacional de Química (ENEQ), destinados a la Muestra de Materiales Didácticos de Química (MOMADIQ), que impliquen prácticas pedagógicas inclusivas. Los resultados producidos discuten la constitución de los procesos coletivos, que reflejan la importancia de la producción y desarrollo de los juegos didácticos, en la formación del sujeto, tanto en la base concebida de los conocimientos científicos, como en la construcción de la subjetividad.

Palabras clave: Alternative methodologies; Inclusive education; Ensenãnza; Inclusive practices.

\section{Introdução}

A educação inclusiva vem sendo cada mais discutida no âmbito educacional pelo recorrente aumento do ingresso de alunos com deficiências nesses espaços. Entretanto, tem ocasionado receios e insegurança nos professores que atuam nestas instituições de ensino por não saberem lidar com essa realidade (Vilela \& Benite, 2010). Com isso, as escolas necessitam de adaptações físicas e pedagógicas, bem como uma reformulação em sua infraestrutura e seus currículos para que possa oferecer a todos os educandos um ensino que propicie sua formação independente de suas necessidades. Tal discussão se mostra necessária para que se possa adentrar em uma questão fundamental para o caminho traçado por uma sociedade, que é a educação (Serpa et al., 2021).

De acordo com Neves, Rahme e Ferreira $(2019$, p.8) “a Educação Especial passa a integrar a proposta pedagógica da escola regular, a partir da identificação, elaboração e organização dos recursos pedagógicos e de acessibilidade que eliminem barreiras para a plena participação dos alunos[...]”. Assim sendo, a inclusão escolar é um modo de inserção, na qual a escola deve assegurar uma educação de qualidade para os alunos (Gritti \& Rodrigues, 2019). E além disso, a participação da família fortalece ainda mais o desenvolvimento que tangem os processos de ensino e aprendizagem (Franco \& Schutz, 2019).

No Ensino de Química, a inclusão representa um grande desafio pelo o alto grau de abstração dos conceitos, presença de elementos visuais relacionados ao fazer científico e a existência de linguagem e terminologia específicas da Química (Benite, et al., 2014; Souza \& Silveira, 2012). Muitos alunos e alunas demonstram dificuldades em aprender química, nos diversos níveis do ensino, por não perceberem o significado ou a validade do que estudam (Gelamo et al., 2013). Desta forma, necessita-se de uma preocupação com os mecanismos de linguagem e as ferramentas didáticas que contemplem a compreensão do educando com necessidade especial. O professor, como o outro mais experiente em uma interação social tem de introduzir os alunos no uso das linguagens próprias de cada disciplina (Carvalho, 2013).

Vilela e Benite (2010) apontam uma percepção segregacionista para o Ensino de Química, uma vez que é recorrente sua redução como área experimental. Os autores relatam que ações usuais como, por exemplo, a visualização de alterações no aspecto de determinados compostos, são considerados como pré-requisito para a compreensão dos referidos conceitos, podendo ser um empecilho para os processos inclusivos.

Diante disso, "para a maioria das pessoas, ser químico pressupõe um cientista hábil no trabalho em laboratório, circundado de líquidos coloridos e representações atômicas e moleculares tridimensionais" (Camargo, et al., 2007, p. 129), percebe-se assim uma limitação que essas concepções podem trazer para um trabalho inclusivo, caso estes não sejam problematizados.

Nesse sentido, falar da educação inclusiva no Ensino de Química (EQ) é importante para desmistificar essa ideia de que alunos com necessidades especiais não constroem um conhecimento sobre os conteúdos conceituais desta ciência. Pensar e falar sobre o tema é uma forma de contornar as recorrentes dificuldades, uma vez que estratégias podem ser buscadas de modo a respeitar as necessidades dos alunos em sala de aula, além de contribuir como caminhos alternativos para a inserção de uma educação inclusiva no Ensino de Química (EQ). A partir de tais considerações Retondo \& Silva (2008) discursam a necessidade de metodologias e estratégias utilizadas para efetivar a inclusão no espaço escolar, no intuito de romper preconceitos para expandir um caminho amplo de possibilidades. 
Cunha (2012) afirma que a partir da produção de jogos didáticos, apresentam um potencial muito importante na construção de conhecimentos no EQ. Sendo esse um caminho de possiblidades no intuito de levar a aprendizagem aos educandos. Partindo dessa abordagem Kishimoto (1996) discorre que o jogo didático requer uma sistematização dos conceitos abordados, e potencializa uma construção do conhecimento que atinge a todos os educandos.

Nesse cenário, torna-se necessário que os professores adotem as práticas inclusivas, mas que os mesmos estejam associados à a cursos formação desses profissionais, realização de eventos que promulguem a diversidade na escola (Gonçalvez, et al., 2013). O presente artigo tem o objetivo de realizar um breve levantamento dos trabalhos produzidos no Encontro Nacional de Química (ENEQ). Posicionando melhor uma discussão muito relevante na construção desse trabalho, a pesquisa por si só, poderia nortear essa discussão, para o campo destinado "inclusão e políticas educacionais" até porque no ENEQ tem um eixo temático que se destina a essas discussões, e seria irrisório afirmar que a quantidade de trabalhos produzidos e discussões que permeiam o campo da deficiência de fato poderia ser bem mais exitosa e expressiva.

Porém a inquietação em focar apenas no MOMADIQ, é pautado na reflexão de Raposo e Mól (2011) que discorrem a necessidade de planejar e desenvolver metodologias, destinada a todos os alunos independentes de suas especificidades, na busca priorizar a aprendizagem.

Uma realidade rotineira docente, é a produção de materiais pedagógicos ou metodologias para alunos com deficiência e outra para os demais alunos, nesse ponto discutir sobre uma Educação Inclusiva perde um pouco o seu significado. E baseando nessas reflexões, a proposta dos trabalhos apresentados no MOMADIQ apresentam essa sensibilidade de tornar visíveis os materiais didáticos na área de Ensino de Química, compilando iniciativas das divulgações de trabalhos que muitas vezes se encontram isolados nos campos educacionais.

\section{Metodologia}

A presente pesquisa se configura em uma abordagem bibliográfica, do tipo qualitativa. De acordo com Ludke e André (2014), a pesquisa qualitativa envolve a obtenção de dados descritivos, supõe um contato direto e prolongado do pesquisador em relação com a situação estudada. Conforme orienta Gil (2010), a pesquisa bibliográfica é elaborada com base em um material que já foi publicado, e sua vantagem reside no fato de permitir ao investigador a cobertura de uma gama de fenômenos.

De acordo com Gil (2010), a realização deste tipo de trabalho ocorre em algumas etapas, tais como: Formulação do problema; elaboração do plano de trabalho; identificação das fontes; leitura do material; fichamento; organização lógica do assunto. No entanto, uma revisão bibliográfica, não precisam seguir exatamente a mesma sequência apresentada, podendo se ajustar conforme as finalidades da pesquisa.

Neste estudo, a revisão bibliográfica foi realizada com base nos anais do Encontro Nacional de Ensino de Química (ENEQ), compreendendo as edições de 2008 (XIX ENEQ - Curitiba/PR), 2010 (XV ENEQ - Universidade de Brasília-UnB), 2012 (XVI ENEQ - Salvador/BA), 2014 (XVII ENEQ - Ouro Preto/MG), 2016 (XIX ENEQ - Florianópolis/SC) e 2018 (XIX ENEQ - Rio Branco/AC), na plataforma de "mostra de materiais didáticos" e/ou "mostra de materiais didáticos de Química (MOMADIQ)". Tal análise se inicia a partir de 2008, pois foi nesta edição que iniciou essas discussões para o compartilhamento de experiências voltadas para a mostra materiais didáticos no ENEQ. Abrindo uma discussão a partir do que se tem produzido nesse evento, com relação aos recursos didáticos (jogos) elaborados para o EQ, envolvendo a constituição de processos coletivos que favorecem a aprendizagem de diferentes envolvidos, reduzindo a um campo de discussão que analisa os trabalhos que permeiam a educação inclusiva.

$\mathrm{Na}$ primeira etapa dessa revisão identificou-se a quantidade de trabalhos produzidos que discorrem em suas metodologias uma abordagem que permeia o Ensino de Química atrelado a educação inclusiva. A seleção desses trabalhos foi 
realizada mediante as especificações dos autores dessas produções ao classificarem na área de conhecimento como: MD - Mostra de materiais didáticos ou MOMADIQ. No segundo ponto de discussão dos resultados são elucidados em consonância com os trabalhos obtidos, delineando alguns apontamentos parafraseados pelos autores com relação ao quantitativo de produções que estão voltadas para alunos surdos, tecendo algumas considerações associadas a essas discussões.

\section{Resultados e Discussão}

O ENEQ é um evento muito importante no EQ, o mesmo ocorre a cada dois anos e os conhecimentos adquiridos e compartilhados, são de fundamental importância para a formação inicial e continuada de professores. Existem vários eixos temáticos no evento, contando também com trabalhos voltados para "inclusão e políticas educacionais". Entretanto, nosso estudo foi realizado no ambiente que expõe os materiais que foram produzidos e desenvolvidos em sala de aula, denominado MOMADIQ, conforme a justificativa apresentada. A produção de materiais didáticos, incluindo os jogos, tem o intuito de inserir o indivíduo no espaço coletivo. Além de também possibilitar o desenvolvimento científico mediado em sala de aula. O Quadro 1 apresenta a síntese dos trabalhos produzidos para o MOMADIQ- ENEQ.

Quadro 1: Trabalhos submetidos no MOMADIQ.

\begin{tabular}{|c|c|c|c|}
\hline ENEQ & $\begin{array}{c}\text { Trabalhos submetidos } \\
\text { envolvendo outras } \\
\text { temáticas }\end{array}$ & $\begin{array}{c}\text { Trabalhos submetidos } \\
\text { envolvendo a educação } \\
\text { inclusiva }\end{array}$ & $\begin{array}{c}\text { Total de trabalhos } \\
\text { submetidos }\end{array}$ \\
\hline $\mathbf{2 0 0 8}$ & 33 & 1 & 34 \\
\hline $\mathbf{2 0 1 0}$ & 61 & 2 & 63 \\
\hline $\mathbf{2 0 1 2}$ & 34 & 4 & 47 \\
\hline $\mathbf{2 0 1 4}$ & 46 & 1 & 75 \\
\hline $\mathbf{2 0 1 6}$ & 61 & 14 & 55 \\
\hline $\mathbf{2 0 1 8}$ & 53 & 2 & \\
\hline
\end{tabular}

Fonte: Autores.

De acordo com o Quadro 1, verificou que apesar de um aumento da quantidade de trabalhos produzidos o quantitativo de trabalhos apresentados nas amostras de materiais didáticos voltados para a educação inclusiva é pequeno. Os trabalhos foram submetidos em forma de pôsteres (resumo), e a análise consistiu em uma leitura, pontuando algumas descrições propostas. Para a discussão dos resultados produzidos, a melhor forma encontrada para representar de forma sucinta essa análise, se encontra no Quadro 2. 
Quadro 2: Análise dos trabalhos submetidos no MOMADIQ.

\begin{tabular}{|c|c|c|}
\hline ENEQ & Trabalhos submetidos envolvendo a educação inclusiva & Descrição \\
\hline 2008 & $\begin{array}{l}\text { Elaboração de Tabelas Periódicas para a facilitação da } \\
\text { aprendizagem de Química para alunos deficientes visuais. } \\
\text { Autores: Carlos A. F. de Oliveira, João B. M. de R. Filho, } \\
\text { Kércya V. de Sousa, Kyara A. C. Limeira, Liliane R. de } \\
\text { Andrade, Poliane K. Batista, Umberto G. da S. Júnior. }\end{array}$ & $\begin{array}{l}\text { Sob o universo abrangente da educação inclusiva, o presente } \\
\text { projeto delimitou sua área de atuação aos alunos portadores } \\
\text { de deficiência visual, elaborando tabelas periódicas, a partir } \\
\text { de materiais alternativos, que facilitem a aprendizagem da } \\
\text { disciplina Química. }\end{array}$ \\
\hline \multirow{2}{*}{2010} & $\begin{array}{c}\text { A química ao alcance das mãos. } \\
\text { Autores: Felipe S. M. Ribeiro, Valéria S. Santos, Willyson R. } \\
\text { J. Araújo, Diego V. L. Gonçalves, Ozelito P. A. Junior, } \\
\text { Rogério de M. Teles. }\end{array}$ & $\begin{array}{l}\text { O intuito é oferecer subsídios ao desenvolvimento de } \\
\text { atividades sem o uso da visão: o conhecimento sensorial } \\
\text { através da manipulação tátil. Deficiência visual. }\end{array}$ \\
\hline & $\begin{array}{l}\text { Desenvolvimento e Diagnóstico de um Kit Didático Inclusivo } \\
\text { sobre Isomeria Constitucional. } \\
\text { Autores: Ernani L. de O. Neto, Alessandra M. T. A. de } \\
\text { Figueirêdo, João B. M. de R. Filho }\end{array}$ & $\begin{array}{l}\text { Por conseguinte, este ensaio consistiu na confecção de um kit } \\
\text { didático (Figura 1) sobre Isomeria Constitucional, para o } \\
\text { ensino de Química, valendo-se de materiais convencionais, e } \\
\text { de seu diagnóstico com educandos normovisuais e DV do } \\
\text { Ensino Médio. Deficiência visual }\end{array}$ \\
\hline \multirow{4}{*}{2012} & $\begin{array}{c}\text { Construção de um dominó químico tátil com materiais } \\
\text { alternativos como forma de auxiliar a aprendizagem em } \\
\text { química orgânica de deficientes visuais. Autores: Débora L. } \\
\text { Rosa, Ana N. F. Mendes }\end{array}$ & $\begin{array}{l}\text { O desenvolvimento de um jogo alternativo para o ensino de } \\
\text { Química, para alunos com deficiência visual, que tem como } \\
\text { objetivo a construção de jogos didáticos escritos em Braille. }\end{array}$ \\
\hline & $\begin{array}{l}\text { Kit de modelo molecular para Química geral e orgânica com } \\
\text { elementos de inclusão social. } \\
\text { Autores: João P. P. Neto, Amanda S. Ramos }\end{array}$ & $\begin{array}{l}\text { A inserção de materiais didático-pedagógicos no ensino de } \\
\text { Química direcionados dentro de uma perspectiva da inclusão } \\
\text { social, no intuito de englobar a alunos com deficiência visual } \\
\text { e com baixa visão. }\end{array}$ \\
\hline & $\begin{array}{l}\text { Construção de um jogo de cartas com elementos de inclusão } \\
\text { social para o ensino de Química a partir da história da tabela } \\
\text { periódica } \\
\text { Autores: Robson F. R. de Araújo, Fabricia de L. Barbosa, } \\
\text { João P. P. Neto }\end{array}$ & $\begin{array}{c}\text { Inserção de elementos necessários a inclusão de deficientes } \\
\text { visuais no ensino regular de Química }\end{array}$ \\
\hline & $\begin{array}{l}\text { Formação de compostos químicos a partir de um jogo de } \\
\text { cartas para o ensino médio de Química com elementos de } \\
\text { inclusão social. } \\
\text { Autores: Alderiza V. de Albuquerque, Alexsandro D. Batista, } \\
\text { João Pessoa Pires Neto }\end{array}$ & $\begin{array}{l}\text { O procedimento de criação do jogo partiu dos seguintes } \\
\text { pressupostos, ter elementos que contemplem os videntes e } \\
\text { cegos, incluindo os de baixa visão na mesma atividade. }\end{array}$ \\
\hline 2014 & $\begin{array}{l}\text { Inclusão social: equipamento facilitador para o estudo de } \\
\text { substâncias iônicas e moleculares. }\end{array}$ & $\begin{array}{c}\text { Elaboração de material didático, utilizado como facilitador da } \\
\text { aprendizagem para alunos com deficiência visual. }\end{array}$ \\
\hline \multirow{3}{*}{2016} & $\begin{array}{l}\text { Artefatos pedagógicos adaptados ao ensino de química para } \\
\text { surdos. } \\
\text { Autores: Amanda B. Pontara, Laís P. Perovano, Ana N. } \\
\text { F.Mendes }\end{array}$ & $\begin{array}{l}\text { Elaboração de artefatos (dominó, bingo e quebra cabeça) que } \\
\text { pudessem facilitar a compreensão da química, visando um } \\
\text { aprendizado mais significativo tanto para alunos tidos como } \\
\text { "normais", como também a alunos com surdez. }\end{array}$ \\
\hline & $\begin{array}{l}\text { Material didáticos de química orgânica para alunos portadores } \\
\text { de deficiência visual. } \\
\text { Autores: Admildo C. de Freitas, Patrícia F, Stein, Adeguimar } \\
\text { P. Fiorotti }\end{array}$ & $\begin{array}{c}\text { Trabalhar os conteúdos de Química orgânica, utilizando } \\
\text { materiais de alto relevo, com alunos portadores de } \\
\text { deficiência visual. }\end{array}$ \\
\hline & $\begin{array}{l}\text { Os elementos químicos ensinados a alunos portadores de } \\
\text { necessidades especiais: uma proposta de material didático. } \\
\text { Autores: Anike A. Arnaud, Leila Inês F. Freire }\end{array}$ & $\begin{array}{l}\text { Produção de um material didático que consistia em pequenas } \\
\text { esferas de isopor revestidas com diferentes materiais, que por } \\
\text { conta das diferentes texturas proporcionavam a diferenciação } \\
\text { dos elementos químicos representados, através da sensação } \\
\text { tátil. O material didático produzido pode ser utilizado não }\end{array}$ \\
\hline
\end{tabular}




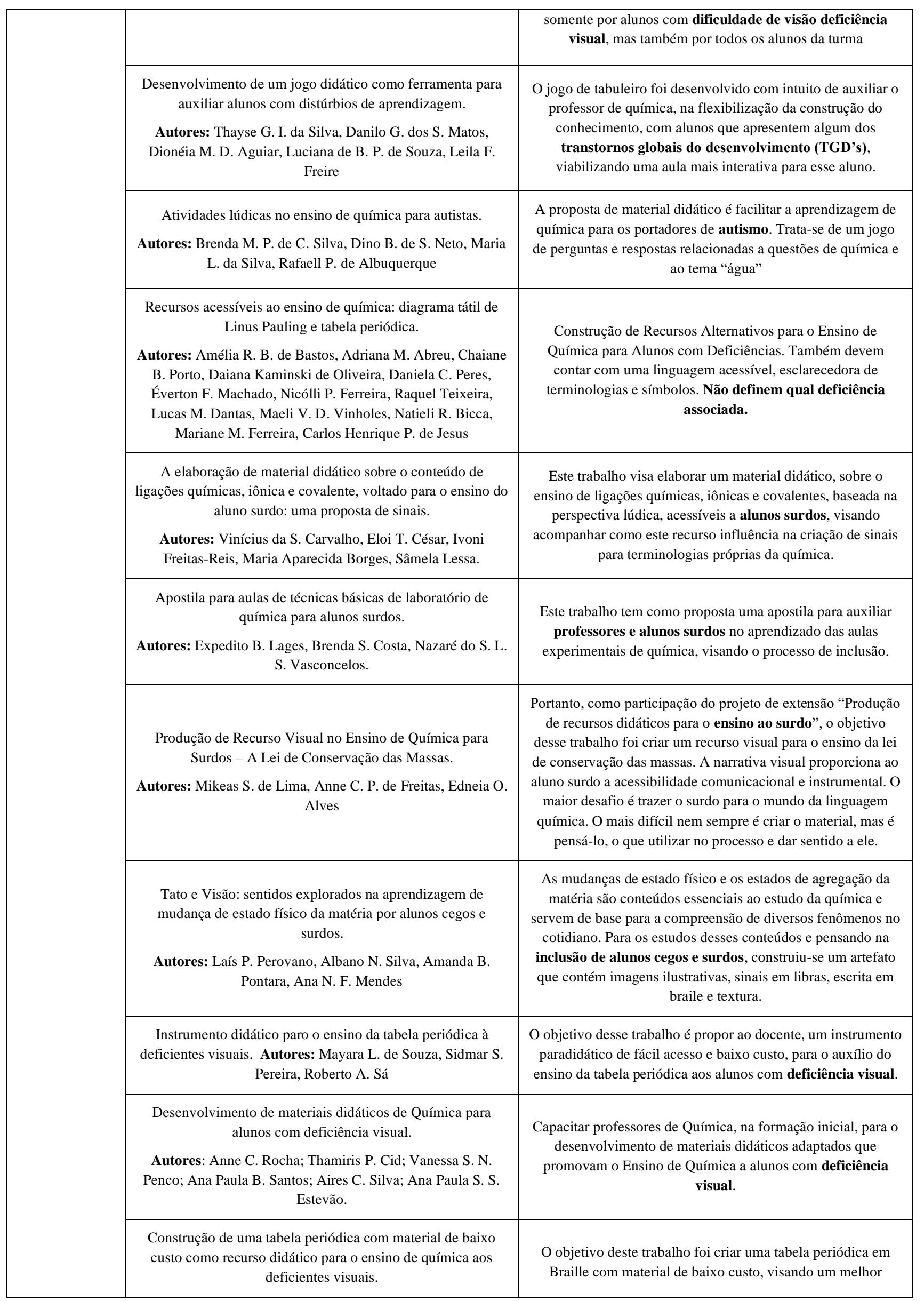


Research, Society and Development, v. 10, n. 6, e9510615574, 2021

(CC BY 4.0) | ISSN 2525-3409 | DOI: http://dx.doi.org/10.33448/rsd-v10i6.15574

\begin{tabular}{|c|c|c|}
\hline & $\begin{array}{l}\text { Autores: Hélvio S. A. de Sousa, Sérgio L. M. Viroli, Sérgio } \\
\text { G. Viroli, Jéssica N.de Almeida, Matheus L. Ramos }\end{array}$ & $\begin{array}{l}\text { rendimento na disciplina de Química pelos alunos com } \\
\text { deficiência visual na educação básica. }\end{array}$ \\
\hline & $\begin{array}{l}\text { A utilização de modelos sobre os estados físicos da matéria } \\
\quad \text { voltados para portadores de deficiências visuais. } \\
\text { Autores: Samara B. Campos, Yara D. de Sousa, Antonielle C. } \\
\text { da F. Camargos, Eliane A. R. Pereira, Gisele G. Halfeld, } \\
\text { Samuel L. Silva, Thiago Vale, Alessandro D. T. Gomes }\end{array}$ & $\begin{array}{l}\text { Detalha a produção de um material didático destinado ao } \\
\text { ensino sobre os estados físicos da matéria para alunos } \\
\text { portadores de deficiência visual, no qual o tato é o principal } \\
\text { sentido utilizado. }\end{array}$ \\
\hline \multirow{2}{*}{2018} & $\begin{array}{l}\text { Recurso paradidático no Ensino de Soluções para estudantes } \\
\text { deficientes visuais. } \\
\text { Autores: Matheus A. dos Santos, Brenda O. Dantas, João V. } \\
\text { N. Vieira, } \\
\text { Andréa de L. Lira, Roscellino B. de M. Júnior. }\end{array}$ & $\begin{array}{l}\text { Utilização de um material paradidático de baixo custo e de } \\
\text { fácil abordagem, para alunos deficientes visuais do Ensino } \\
\text { Médio, com relação ao conteúdo de diluição e misturas de } \\
\text { soluções. }\end{array}$ \\
\hline & $\begin{array}{l}\text { Jogos Didáticos como Abordagem Didática na Formação } \\
\text { Inicial de Professores de Química } \\
\text { Autores: Antônio C. de S. Pereira; Luan dos S. de Lima; } \\
\text { Leonardo S. de Araújo; Gahelyka A. P. Souza; Tyson L. A. } \\
\text { Freire }\end{array}$ & $\begin{array}{l}\text { Esta pesquisa busca investigar quais dos jogos didáticos } \\
\text { elaborados pelos estudantes do curso de Licenciatura em } \\
\text { Química, da Universidade Federal do Acre (UFAC), são } \\
\text { destinados a inclusão de estudantes deficientes nas aulas de } \\
\text { Química. Não detalham qual deficiência. }\end{array}$ \\
\hline
\end{tabular}

Fonte: Autores.

Fazendo uma breve reflexão com relação ao que foi apresentado no Quadro 2, dos 25 trabalhos identificados, 16 deles são voltados para alunos com alguma deficiência visual. Complementando essa discussão, Raposo \& Mól (2011), discutem que o EQ deve contemplar seus três níveis de abordagem: macroscópico, microscópico e representacional. No EQ compreender o campo representacional tem um peso muito grande, na construção do entendimento dos conceitos científicos. Desta forma do campo de vista "representacional", quando se discute a produção de materiais ou jogos didáticos na química, a maioria das discussões perpassam apenas pelo campo da deficiência visual. A Figura 1 abaixo reflete o panorama dos trabalhos que foram encontrados, e de forma mais simplifica amplia essas reflexões que foram mencionadas no parágrafo anterior.

Figura 1: Trabalhos apresentados no ENEQ/MOMADIQ (2008 a 2018) - Educação Inclusiva.

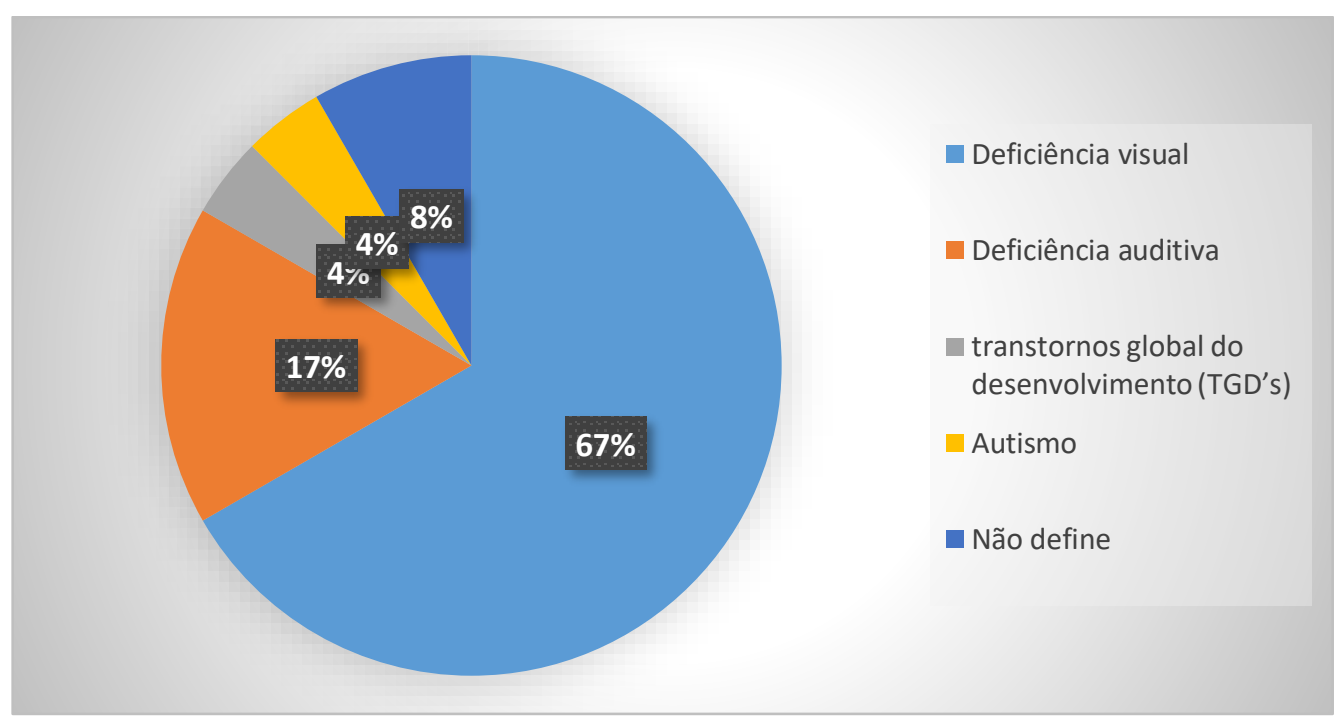

Fonte: Autores. 
De uma forma geral parte das produções delineiam discussões que também se direcionam a outras deficiências, e isso se faz fundamental no ambiente escolar pois fundamenta a necessidade de ampliar o olhar para essa diversidade, no intuito de sistematizar a flexibilização da construção do conhecimento. E essa relação dialógica cria o espaço de aprendizagem e ensino, com relação aos alunos.

Nessa interface, a aprendizagem no meio social, desencadeia um verdadeiro desenvolvimento, a produção de jogos e materiais que estimulem essa interação e tais apontamentos se encontram nas descrições dos trabalhos apresentados no MOMADIQ. Cunha (2012) afirma que a utilização de jogos didáticos no EQ deve contribuir para formação social do estudante, pois os jogos promovem o debate e a comunicação em sala de aula.

Da mesma forma que Vygotsky (2000), discorre que a criança cega ou surda pode alcançar o mesmo desenvolvimento que a criança normal, no entanto, com relação às outras deficiências a peculiaridades dos caminhos indiretos mediados pelo professor, se torna mais restrito. Fernandes \& Freitas-Reis (2017, p.187) afirmam que é necessário criar condições para a participação no ambiente escolar, que a educação consiste em propiciar ao indivíduo, pela diversidade de oportunidades e principalmente norteando o conhecimento de si e do mundo, no intuito de ampliar a chance de se tornar um cidadão.

Os resultados permitem discutir sobre a importância do jogo no EQ, e nesse cenário Santos (2002, p. 12), afirma que “[...] o desenvolvimento do aspecto lúdico facilita a aprendizagem, o desenvolvimento pessoal, social e cultural, colabora para uma boa saúde mental [...]". Portanto, mesmo que o desenvolvimento da criança seja complicado, pelo defeito não quer dizer que ela é menos desenvolvida, mas que se desenvolve de outra forma (Vygotsky, 2007). E esses alunos não devem ficar privados de atividades que são desenvolvidas para a turma de forma geral, por isso é necessário possibilitar outros caminhos que possibilitem esse processo de socialização dos alunos com deficiência no ambiente escolar. Assim sendo essa compensação só é possível pelos caminhos indiretos que são introduzidos pelos docentes (Vygotsky, 2007).

A exemplo disso os trabalhos intitulados: "Artefatos pedagógicos adaptados ao ensino de química para surdos" e "Os elementos químicos ensinados a alunos portadores de necessidades especiais: uma proposta de material didático", visam a diversidade na aprendizagem, não se reduzindo apenas a processos voltados à inclusão de alguns alunos, mas que englobe todos os discentes, dentro da sua metodologia. Atualmente sabemos que o termo "portadores de necessidades especiais" é inadequado, pois dá uma ideia de transitoriedade a uma condição, muitas vezes permanente, além de reforçar a ideia de um peso social. A expressão mais adequada é "pessoa com deficiência", no entanto, o artigo preserva as expressões que foram utilizadas pelos autores nos trabalhos. Silva \& Dutra (2020, p.433) afirmam que o "Ensino de Química precisa oferecer aos estudantes com deficiência subsídios que possibilite o desenvolvimento de uma visão crítica e articulada do mundo que o cerca, podendo analisar, compreender e utilizar os conhecimentos químicos". Nesse sentido, o saber está relacionado e comprometido com a prática do discente (Serpa et al., 2021).

É preciso frisar que cada deficiência apresenta diferentes abordagens metodológicas. E quando levamos essa discussão para o EQ, uma breve reflexão é que o conhecimento científico dentro do EQ, se torna de grande importância. Mas se observarmos o desenvolvimento do sujeito, a construção da sua subjetividade também é fundamental. Um aluno com deficiência mental, por exemplo, é preciso que seja mediado uma busca a significação da constituição do sujeito simbólico, a aprendizagem se direciona a partir de outros caminhos, e não pela apropriação dos conceitos científicos. Portanto, existe essa necessidade de enxergar o aluno como um sujeito historicamente constituído a partir de suas relações no ambiente escolar. E os trabalhos apresentados no MOMADIQ trazem essa preocupação em desenvolver materiais que busquem integrar todos os alunos dentro de suas especificidades. Isso mostra que o EQ no ambiente escolar não se reduz apenas em atividades experimentais (Sales, 2020).

Por fim, em decorrências das articulações e discussões obtidas ao longo da pesquisa, observa-se um avanço gradativo voltado para as práticas inclusivas no Ensino, no entanto a de se considerar que existe um caminho a ser percorrido, e que em 
meio a tantos entraves existe a persistência em levar para o próximo aquilo que ele não pode ser privado que é a Educação, e uma Educação de qualidade.

\section{Conclusão}

No início desse trabalho me propus tecer algumas considerações sobre o ensino de química, buscando encontrar nas minhas falas a Química das salas de aula, descontextualizada e difícil compreensão. Dessa forma, o que se percebe, é que muitas vezes a questão da prática profissional do professor é vista por ele como essencialmente simples, onde basta saber alguns conteúdos e passá-los aos alunos para que devolvam da maneira como ele pede, sem levar em consideração os pensamentos externos trazidos pelos alunos em sala de aula. Com isso, a relação professor-aluno vem a se resumir estritamente dentro do âmbito escolar.

Entretanto, é necessário elaborar e implementar uma proposta para o Ensino da Química mais coerente com as necessidades reais dos alunos, incluindo os mesmos neste processo. Uma proposta problematizadora e atuante no meio e que, também, considere o aluno além de um sujeito possuidor de um conhecimento, e que traz consigo diversas vivências do seu cotidiano, vem a ser um componente essencial dos processos de ensino e aprendizagem. Pode ser bom ou ruim, mas o professor não deve negligenciar o que é trazido pelo educando nesse processo, sejam problemas, emoções, dificuldades, etc.

Como é largamente conhecido na esfera da educação em ciências, as velhas estratégias de ensino como o quadro e giz/pincel, são insuficientes em assegurar que os discentes, realmente aprendam os conceitos científicos. Sabemos que o processo de ensino e aprendizagem é complexo, mutável no tempo, envolve múltiplos saberes e está longe de ser fácil.

Por essa razão temos a consciência de que o Ensino de Química deva ser trabalhado com o objetivo de despertar o interesse por conteúdos muitas vezes abstratos e aparentemente sem nenhuma relação com o dia-a-dia do aluno. Mas que como sujeitos da ação que somos, entender o outro é também compreender a sua matriz histórica e isso reflete diretamente no que quero construir em sala de aula juntamente com meus alunos.

Para os trabalhos futuros, a partir desse artigo foi possível perceber que é necessário ampliar ainda mais a pesquisa voltada para a Educação inclusiva nos espaços escolares voltados para a Educação Básica, porém como essas discussões se aplicam no Ensino Superior dentro do ambiente universitário, desta forma isso surge como uma inquietação e ao mesmo tempo uma necessidade.

\section{Referências}

Benite, A. M. C., Batista, M. A. R. S., Silva, L. D. \& Benite, C. R. M. (2014). O Diário Virtual Coletivo: Um Recurso para Investigação dos Saberes Docentes Mobilizados na Formação de Professores de Química de Deficientes Visuais. Química Nova na Escola, (36), 61-70.

Camargo, E. P., Santos, S. de L. R. dos, Nardi, R., \& Veraszto, E. V. Alunos com deficiência visual em um curso de química: fatores atitudinais como dificuldades educacionais (2007). Alunos com deficiência visual em um curso de química: fatores atitudinais como dificuldades educacionais. Anais ABRAPEC. Florianópolis, Brasil.

Carvalho, A. M. P. de. (2013) Formação de professores de Ciências: duas epistemologias em debate. Trabalho completo do IX congresso internacional sobre investigación em didáctica de las ciências X, Girona, Espanha.

Cunha, M. B. (2012). Jogos no Ensino de Química: Considerações teóricas para sua utilização em sala de aula. Química Nova na escola, 34 (2), $92-98$.

Fernandes, J. M. \& Freitas-Reis, I. (2017) Estratégia didática inclusiva a alunos surdos para o ensino dos conceitos de balanceamento de equações químicas e de estequiometria para o ensino médio. Química nova na escola, 39 (2), 86-194.

Franco, A. M. dos S. \& Schutz, G. E. (2019). Sistema educacional inclusivo constitucional e o atendimento educacional especializado. Saúde e Debate, 43, 244255 .

Gelamo, M. R., Gonçalvez, M. C., Rosa, T. F. de \& Belli, J. I. R. Ensinando Química para séries iniciais do Ensino Fundamental: Uma experiência dos acadêmicos de Licenciatura em Química. (2013). Resumo do XI congresso nacional de Educação-ÉDUCERE, XI, Curitiba, Brasil.

Gil, A. C. (2010). Como elaborar projetos de pesquisa. (4a ed.), Atlas. 
Research, Society and Development, v. 10, n. 6, e9510615574, 2021

(CC BY 4.0) | ISSN 2525-3409 | DOI: http://dx.doi.org/10.33448/rsd-v10i6.15574

Gonçalves, F. P., Regiani, A. M., Auras, S. R., Silveira, T. S., Coelho, J. C. \& Hobmeir, A. K. T. (2013). A educação Inclusiva na formação de professores e no Ensino de Química: A deficiência visual em debate. Química nova na escola, 35 (4), 264-271.

Gritti, A., \& Rodrigues, A. G. (2019). Os desafios da inclusão escolar. Revista Educação em foco, 11, 1-4.

Kishimoto, T. M. (1996). Jogo, brinquedo, brincadeira e educação. Cortez,

Ludke, M. \& André, M. E. D. A. (2014). Pesquisa em educação: Abordagens Qualitativas. EPU.

Neves, L. R., Rahme, M. M., \& Ferreira, C. M. da R. (2019). Política da Educação Especial e os desafios de uma perspectiva inclusiva. Educação e realidade, 44(1), 1-21.

Raposo, N. P \& Mól, G. S. (2011) A diversidade para aprender conceitos científicos: a ressignificação do Ensino de Ciências a partir do trabalho pedagógico com alunos cegos. In: Santos, W. L. P., Maldaner, O.A. (Org.). Ensino de Química em Foco. Ijuí: Unijuí.

Retondo, C. G. \& Silva, G. M. (2008) Ressignificando a formação de professores de Química para a Educação Especial e Inclusiva: Uma História de Parcerias. Química nova na escola, $30,27-33$.

Sales, P. F. (2020). "Químiemcasa": aspectos de um processo de ensino para a aprendizagem de Química em épocas de pandemia. Research, Scociety and Developmente, 9 (11), e83391110420. https://doi.org/10.33448/rsd-v9i11.10420.

Santos, S. M. P. dos. (2002). O lúdico na formação do educador. (5a ed.), Vozes.

Serpa, L. G., Machado, C. J., Nascimento, G. A. do. \& Almeida, A. R. (2021). Por uma educação a favor da páxis: ação, educação e cultura. Research, Scociety and Developmente, 10 (1), e54210112104. https://doi.org/10.33448/rsd-v10il.12104.

Silva, J. C. da \& Dutra, M. M. (2020) Ensino de Química no contexto da Educação Especial: Uma análise de artigos publicados na Revista Químic a Nova na Escola no período de 1995 a 2016. Revista Prática Docente, 5(1) 431-488.

Sousa, S. F. \& Silveira, H. E. (2012). Terminologias Químicas na Libras: a utilização de sinais na aprendizagem de alunos surdos. Química Nova na Escola, (33), 37-46.

Vilela, E. B. \& Benite, A. M. C. (2010). A Educação inclusiva na percepção dos professores de química. Ciência \& Educação, 16 (3), $585-594$.

Vygotsky, L. S. (1983) Obras Escogidas V-fundamentos de defectologia. Editorial Pedagógica. 